\title{
Correlated levels of cerebrospinal fluid pathogenic proteins in drug-naïve Parkinson's disease
}

Hidetomo Murakami ${ }^{1}$, Takahiko Tokuda ${ }^{2}$, Omar M. A. El-Agnaf ${ }^{3}$, Takuma Ohmichi ${ }^{4}$, Ayako Miki ${ }^{1}$, Hideaki Ohashi ${ }^{1}$, Yoshiyuki Owan ${ }^{1}$, Yu Saito ${ }^{1}$, Satoshi Yano ${ }^{1}$, Tamao Tsukie ${ }^{5}$, Takeshi Ikeuchi ${ }^{5}$ and Kenjiro Ono ${ }^{1^{*}}$ (D)

\begin{abstract}
Background and aim: Toxic oligomeric a-synuclein (aS; O-aS) has been suggested to play a central role in the pathogenesis of Lewy body diseases such as Parkinson's disease (PD). Cerebrospinal fluid (CSF) levels of aS, O-aS, total and phosphorylated tau, and amyloid $\beta$ 1-42 (Aß1-42) are thought to reflect the pathophysiology or clinical symptoms in PD. In this study, we examined correlations of the CSF levels of these proteins with the clinical symptoms, and with each other in drug-naïve patients with PD.

Methods: Twenty-seven drug-naïve patients with PD were included. Motor and cognitive functions were assessed using the Unified Parkinson's Disease Rating Scale (UPDRS), Montreal Cognitive Assessment (MoCA), and Neurobehavioral Cognitive Status Examination (COGNISTAT). CSF levels of total aS, O-aS, A 1 1-42, total tau and tau phosphorylated at threonine 181 (P-tau181p) were measured. CSF levels of these proteins were compared with clinical assessments from the UPDRS, MoCA and COGNISTAT using Spearman correlation analysis. Spearman correlation coefficients among CSF protein levels were also evaluated.

Results: CSF levels of aS were negatively correlated with UPDRS part III (motor score) $(p<0.05)$ and bradykinesia $(p<0.01)$, and positively correlated with COGNISTAT subtest of judgement $(p<0.01)$ and CSF levels of A $1-42$ $(p<0.001)$, total tau $(p<0.001)$ and P-tau181p $(p<0.01)$. Lower CSF levels of A $\beta 1-42$, total tau and P-tau181p were significantly related to worsening of some motor and/or cognitive functions. The CSF level of O-aS showed no correlation with any motor and cognitive assessments or with CSF levels of the other proteins.

Conclusion: CSF levels of aS are correlated with some clinical symptoms and CSF levels of other pathogenic proteins in drug-naïve PD patients. These correlations suggest a central role for interaction and aggregation of aS with $A \beta 1-42$, tau, and phosphorylated tau in the pathogenesis of PD. Although O-aS has been shown to have neurotoxic effects, CSF levels do not reflect clinical symptoms or levels of other proteins in cross-sectional assessment.
\end{abstract}

Keywords: Parkinson's disease, a-Synuclein, Oligomer, Amyloid $\beta$-protein (1-42), Tau protein, Clinical symptom

\footnotetext{
* Correspondence: onoken@med.showa-u.ac.jp

${ }^{1}$ Department of Neurology, School of Medicine, Showa University, 1-5-8

Hatanodai, Shinagawa-ku, Tokyo 142-8666, Japan

Full list of author information is available at the end of the article
}

(c) The Author(s). 2019 Open Access This article is distributed under the terms of the Creative Commons Attribution 4.0 International License (http://creativecommons.org/licenses/by/4.0/), which permits unrestricted use, distribution, and reproduction in any medium, provided you give appropriate credit to the original author(s) and the source, provide a link to the Creative Commons license, and indicate if changes were made. The Creative Commons Public Domain Dedication waiver (http://creativecommons.org/publicdomain/zero/1.0/) applies to the data made available in this article, unless otherwise stated. 


\section{Background}

Parkinson's disease (PD) is a common neurodegenerative disorder, but diagnosis based on assessment of clinical symptoms and radiological findings can be difficult, especially in the early phase. Therefore, biomarkers reflecting the pathophysiology of PD are required, and pathogenic proteins related to neurodegeneration in cerebrospinal fluid (CSF) may be candidates as such biomarkers. The pathological hallmark of PD is the presence of Lewy body, that is, abnormal aggregates of $\alpha$-synuclein $(\alpha S)$ in the brain. Recently, oligomeric $\alpha$-synuclein $(\mathrm{O}-\alpha \mathrm{S})$ has been shown to have neurotoxic effects, and such oligomers may play a central role in the pathogenesis of PD [1-3]. Most studies of CSF levels of total $\alpha S$ and O- $\alpha S$ have shown that total $\alpha S$ is decreased in $\mathrm{PD}$ patients compared to normal controls $[4,5]$, while $\mathrm{O}-\alpha \mathrm{S}$ is increased in PD [4-6]. Therefore, CSF levels of total $\alpha \mathrm{S}$ and $\mathrm{O}-\alpha \mathrm{S}$ may reflect progression of the pathological background and clinical symptoms in patients with PD and may be candidate biomarkers for PD.

In Alzheimer's disease (AD), the CSF level of amyloid $\beta$ (A $\beta) 1-42(A \beta 1-42)$ is decreased and that of tau is increased [7]. These proteins are established biomarkers for diagnosis of $\mathrm{AD}$, and $\mathrm{PD}$ can present with $\mathrm{AD}$ pathology such as senile plaques and neurofibrillary tangles [8]. Previous studies comparing CSF levels of these potential biomarkers between PD cohorts and controls have shown that A $\beta 1-42$, total tau and phosphorylated tau (phosphorylated at threonine 181; P-tau181p) are significantly decreased in PD [9]. These findings suggest that the levels of these proteins in CSF are related to the pathological background of PD patients. Tau plays an important role in the structural integrity of the neuron, and phosphorylation of tau reduces its binding affinity for microtubules and causes self-aggregation, which results in neuronal damage [10]. In contrast, CSF levels of these proteins in PD are correlated with each other. For example, total $\alpha \mathrm{S}$ levels are positively correlated with the levels of total tau $[4,5]$, phosphorylated tau $[4,5]$ and A $\beta 1-42$ [4]. These correlations suggest interactions between these proteins.

Many studies in PD patients at various clinical stages and under different medication have shown correlations between CSF levels of the candidate biomarker proteins and clinical symptoms, but the results have not necessarily agreed among studies. Correlations of CSF levels of these proteins with motor and cognitive functions are rarely compared in drug-naïve PD patients. Therefore, in this study, we examined correlations of motor and cognitive functions, and CSF protein levels only in drugnaïve PD patients.

\section{Material and methods}

\section{Patients}

Twenty-seven patients with de novo PD were enrolled in the study. Diagnosis of PD was made according to MDS clinical diagnostic criteria for PD [11]. Patients were first diagnosed based upon their clinical history and neurological findings before medication. The diagnosis of PD was confirmed when motor symptoms improved with dopaminergic medication. Clinical and CSF data for this study were obtained within the two months before medication. MRI findings in all participants indicated no abnormal intensity area or focal atrophy suggesting parkinsonism other than PD. Patients with dementia with Lewy bodies (DLB) based on the fourth consensus report of the DLB consortium [12] were excluded. None of the participants had apparent cognitive impairment before and at least 1 year after onset of parkinsonism. Therefore, our participants had a spectrum from PD with normal cognition to PD with dementia (PDD) through PD with mild cognitive impairment (PD-MCI). To exclude the effects of medication on clinical assessments and CSF protein levels, we focused on drug-naïve PD patients. None of the patients had any other disease or were taking medications that might affect motor and cognitive function.

\section{Collection of CSF}

Lumbar puncture was performed at the vertebral interspaces of L3-L4 or L4-L5 in a fasting state before treatment. The first $5 \mathrm{ml}$ of CSF was used for routine examination, and the next $10 \mathrm{ml}$ was used for this study. The CSF sample was collected in a sterile polypropylene tube and centrifuged for $10 \mathrm{~min}$ at $400 \mathrm{~g}$ within $10 \mathrm{~min}$ after completion of lumbar puncture. The supernatant was packed in a polypropylene microtube and stored at $-80^{\circ} \mathrm{C}$ until assays were performed.

\section{Immunoassay of total aS and O-aS in CSF}

CSF total $\alpha \mathrm{S}$ was analyzed using a commercially available enzyme-linked immunosorbent assay (ELISA) kit (Covance, Dedham, MA) [13, 14]. Briefly, $200 \mu \mathrm{L} /$ well of diluted $\alpha S$ standards (range, 6.1-1500 pg/mL) using reconstituted stock and diluted CSF samples $(200 \mu \mathrm{L} /$ well $)$ were added to the capture antibody-coated plate. After overnight incubation of the plate at $2-8^{\circ} \mathrm{C}$ with shaking, $50 \mu \mathrm{L} /$ well of biotinylated detector antibody was added followed by incubation for $2 \mathrm{~h}$ at room temperature. Diluted streptavidin horseradish peroxidase was added, and the plate was incubated at room temperature for $1 \mathrm{~h}$. After washing, a mixture of 2 different chemiluminescent substrates was added and end-point luminescence was read with a microplate luminometer (SpectraMax L, Molecular Device, Tokyo). The concentration of $\alpha \mathrm{S}$ was measured using standard curves with 4-parameter curve fitting.

The levels $\mathrm{O}-\alpha \mathrm{S}$ in CSF samples were measured using a single antibody sandwich ELISA, as described previously with some modification [6, 15]. An ELISA 96-well plate (Nunc Maxisorb; NUNC, Denmark) was coated by overnight incubation at $4{ }^{\circ} \mathrm{C}$ with $1 \mu \mathrm{g} / \mathrm{mL}$ of the anti-human 
$\alpha \mathrm{S}$ monoclonal antibody 211 (Syn211; Thermo Fisher Scientific, IL), which recognizes amino acid residues 121-125 of human $\alpha \mathrm{S}$, in $200 \mathrm{mM} \mathrm{NaHCO} 3$, pH $9.6(100 \mu \mathrm{L} /$ well). The plate was washed with phosphate buffered saline containing $0.05 \%$ Tween20 (PBS-T) and incubated with $200 \mu \mathrm{L} /$ well of blocking buffer, which is PBS-T containing $2.5 \%$ gelatin, for $2 \mathrm{~h}$ at $37^{\circ} \mathrm{C}$. After washing $200 \mu \mathrm{L} /$ well of PBS-T, $100 \mu \mathrm{L}$ CSF containing 1\% cocktail of protease inhibitors (Protease Inhibitor Cocktail Set I; Calbiochem, Millipore, CA) and 5\% heterophilic antibody inhibitor (ELISA diluent; MABTECH, Sweden) were added to each well, and then incubated at $37^{\circ} \mathrm{C}$ for an additional $3 \mathrm{~h}$. Biotinylated 211 monoclonal antibody diluted to $1 \mu \mathrm{g} / \mathrm{mL}$ in blocking buffer was added and incubated at $37^{\circ} \mathrm{C}$ for $2 \mathrm{~h}$. The plate was washed and then incubated for $1 \mathrm{~h}$ at $37^{\circ} \mathrm{C}$ with $100 \mu \mathrm{L} /$ well of ExtrAvidin-Peroxidase (Sigma-Aldrich, Dorset, UK) diluted 1:1000 in blocking buffer. The plate was washed and incubated with $200 \mu \mathrm{L} /$ well of an enhanced chemiluminescent substrate (Super-Signal ELISA Femto, Pierce Biotechnology), after which chemiluminescence in relative light units was immediately measured with a microplate luminometer (SpectraMax L, Molecular Device, Tokyo). All the samples were measured in 1 plate to avoid plate-to-plate variations.

For both immunoassays, the samples were screened in blind fashion and were randomly tested.

\section{Immunoassay of total tau, P-tau181p and $A \beta 1-42$}

We used the multiplex xMAP Luminex platform with Innogenetics immunoassay kit-based reagents for the CSF biomarker measurements of P-tau181p, total tau, and A $31-42$ (INNO-BIA ALzBio3, Ghent, Belgium) $[16,17]$. Briefly, the Innogenetics kit reagents includes well-characterized capture monoclonal antibodies specific for A $\beta 1-42$ (4D7A3), total tau (AT120), and Ptau181p (AT270), each chemically bonded to unique sets of color-coded beads, and analyte-specific detector antibodies (HT7, 3D6). All analyses were performed in duplicate in accordance with the platform for Japanese ADNI biomarker measurement [18] and while blinded to clinical data, and batch-wise on one occasion, by a board-certified laboratory technician at the Department of Molecular Genetics, Niigata University. Intra-assay coefficients of variation were below $10 \%$.

\section{Assessment of clinical symptoms}

The Unified Parkinson's Disease Rating Scale (UPDRS) [19] was used for assessment of motor function. This scale was assessed using the total score for Part III (motor score) and subscores for tremor (items 16, 20, 21), rigidity (item 22), bradykinesia (items 23 to 26 and 31), gait (items 13 to 15 and 29), and postural instability (items 27, 28 and 30). Cognitive function was assessed with the Montreal Cognitive Assessment (MoCA) and the Neurobehavioral Cognitive Status Examination (COGNISTAT). These neuropsychological tests were performed by examiners who were blinded to motor assessment and CSF findings. The MoCA is used to detect $\mathrm{MCI}$ and has a best score of 30 . The COGNISTAT has 10 separate cognitive subtests: orientation, attention, languagecomprehension, language-repetition, language-naming, construction, memory, calculation, similarity, and judgment [20]. In the Japanese version of the COGNISTAT, the raw score of each subtest is converted to a standard score, in which average scores in normal controls are set to 10 and standard deviations (SD) in healthy controls are set to 1 [21]. For cognitive assessment using the COGNISTAT, we used the standardized score of each subtest. We have shown that the MoCA and COGNISTAT are sensitive for detection of subtle cognitive impairment in PD patients [22].

\section{Statistical analysis}

CSF levels of proteins were compared with clinical assessments from the UPDRS, MoCA and COGNISTAT. Correlations among CSF protein levels were also evaluated. Correlation coefficients were calculated using Spearman correlation analysis. The level of significance was $p<0.05$ (two-tailed probability).

\section{Results}

The participants included 14 males and 13 females. Three patients did not undergo the UPDRS and MoCA, and 8 did not take the COGNISTAT. CSF samples of all participants were watery clear and not bloody. Red blood cells were not observed microscopically in sediments of the CSF. CSF levels of P-tau181p in 2 patients were below the detection sensitivity and were excluded in analyses using P-tau181p. The number of participants in calculation of each correlation coefficient is shown in Tables 1, 2 and 3. The background of patients is shown in Table 4.

Spearman correlation coefficients of each CSF protein level with patient background and motor symptoms are shown in Table 1, and those with cognitive assessment scores are given in Table 2. For patient background, CSF levels of total $\alpha \mathrm{S}, \mathrm{O}-\alpha \mathrm{S}, \mathrm{A} \beta 1-42$ and total tau were not correlated with age, education, or duration from symptom onset, but P-tau181p was positively correlated with age $(p<0.05)$. For clinical symptoms, CSF levels of total $\alpha \mathrm{S}$ were negatively correlated with UPDRS scores for part III $(p<0.05$, Fig. 1a) and bradykinesia $(p<0.01$, Fig. $1 \mathrm{~b})$, and positively correlated with the COGNISTAT subscore for judgment $(p<0.01$, Fig. $1 \mathrm{c})$; $\mathrm{O}-\alpha \mathrm{S}$ showed no correlation with any motor and cognitive assessments; $A \beta 1-42$ was positively correlated with MoCA score $(p<0.05)$; total tau was negatively correlated with the UPDRS subscore for bradykinesia $(p<0.05)$ and positively correlated with 
Table 1 Spearman correlation coefficients of each CSF protein level with patient background and motor symptoms

\begin{tabular}{|c|c|c|c|c|c|c|c|c|c|c|}
\hline & \multicolumn{4}{|c|}{ Patient background } & \multicolumn{6}{|c|}{ Motor symptoms } \\
\hline & & Age & Education & $\begin{array}{l}\text { Duration from } \\
\text { symptom onset }\end{array}$ & UPDRS part III & Tremor & Rigidity & Bradykinesia & Gait & Postural instability \\
\hline \multirow[t]{3}{*}{ Total as } & $r$ & 0.362 & 0.216 & -0.314 & $-0.446^{*}$ & 0.192 & -0.331 & $-0.528^{* *}$ & -0.245 & -0.356 \\
\hline & $p$ & 0.0635 & 0.2794 & 0.1104 & 0.0289 & 0.3692 & 0.1136 & 0.0080 & 0.2482 & 0.0873 \\
\hline & $n$ & 27 & 27 & 27 & 24 & 24 & 24 & 24 & 24 & 24 \\
\hline \multirow[t]{3}{*}{ O-aS } & $r$ & 0.010 & -0.036 & 0.203 & -0.205 & 0.265 & -0.119 & -0.224 & -0.335 & -0.310 \\
\hline & $p$ & 0.9614 & 0.8594 & 0.3105 & 0.3356 & 0.2101 & 0.5792 & 0.2928 & 0.1095 & 0.1407 \\
\hline & $n$ & 27 & 27 & 27 & 24 & 24 & 24 & 24 & 24 & 24 \\
\hline \multirow[t]{3}{*}{$A \beta 1-42$} & $r$ & 0.292 & 0.131 & -0.231 & -0.085 & 0.140 & -0.024 & -0.107 & -0.160 & -0.047 \\
\hline & $p$ & 0.1389 & 0.5150 & 0.2473 & 0.6913 & 0.5141 & 0.9104 & 0.6203 & 0.4546 & 0.8283 \\
\hline & $n$ & 27 & 27 & 27 & 24 & 24 & 24 & 24 & 24 & 24 \\
\hline \multirow[t]{3}{*}{ Total tau } & $r$ & 0.334 & 0.180 & -0.212 & -0.297 & 0.002 & -0.195 & $-0.426^{*}$ & -0.167 & -0.163 \\
\hline & $p$ & 0.0886 & 0.3702 & 0.2877 & 0.1581 & 0.9934 & 0.3610 & 0.0379 & 0.4346 & 0.4457 \\
\hline & $n$ & 27 & 27 & 27 & 24 & 24 & 24 & 24 & 24 & 24 \\
\hline \multirow[t]{3}{*}{ P-tau181p } & r & $0.491^{*}$ & 0.081 & -0.032 & $-0.448^{*}$ & 0.029 & $-0.425^{*}$ & $-0.462^{*}$ & -0.048 & -0.338 \\
\hline & $p$ & 0.0126 & 0.7004 & 0.8804 & 0.0365 & 0.8978 & 0.0486 & 0.0303 & 0.8317 & 0.1241 \\
\hline & $\mathrm{n}$ & 25 & 25 & 25 & 22 & 22 & 22 & 22 & 22 & 22 \\
\hline
\end{tabular}

*: $p<0.05 * *: p<0.01$

Abbreviations: Total aS, Total a-synuclein; O-aS, Oligomeric a-synuclein; P-tau181p, tau phosphorylated at threonine 181; UPDRS Unified Parkinson's Disease Rating Scale

Table 2 Spearman correlation coefficients of each CSF protein level with cognitive assessment scores

\begin{tabular}{|c|c|c|c|c|c|c|c|c|c|c|c|c|}
\hline \multirow{2}{*}{\multicolumn{2}{|c|}{$\frac{\text { Battery }}{\text { Subtests }}$}} & \multirow{2}{*}{$\begin{array}{l}\text { MoCA } \\
\text { Total } \\
\text { score }\end{array}$} & \multicolumn{10}{|l|}{ COGNISTAT } \\
\hline & & & Orientation & Attention & $\begin{array}{l}\text { Language- } \\
\text { comprehension }\end{array}$ & $\begin{array}{l}\text { Language- } \\
\text { repetition }\end{array}$ & $\begin{array}{l}\text { Language- } \\
\text { naming }\end{array}$ & Construction & Memory & Calculation & Similarity & Judgement \\
\hline \multirow[t]{3}{*}{ Total as } & $r$ & 0.204 & 0.176 & -0.119 & 0.174 & 0.168 & 0.447 & 0.345 & 0.158 & 0.245 & 0.088 & $0.626^{* *}$ \\
\hline & $p$ & 0.3385 & 0.4706 & 0.6275 & 0.4770 & 0.4914 & 0.0551 & 0.1475 & 0.5171 & 0.3117 & 0.7213 & 0.0041 \\
\hline & $n$ & 24 & 19 & 19 & 19 & 19 & 19 & 19 & 19 & 19 & 19 & 19 \\
\hline \multirow[t]{3}{*}{ O-as } & r & 0.227 & 0.190 & -0.161 & 0.171 & 0.146 & -0.196 & 0.137 & 0.095 & 0.087 & 0.139 & 0.244 \\
\hline & $p$ & 0.2871 & 0.4354 & 0.5091 & 0.4833 & 0.5500 & 0.4216 & 0.5747 & 0.6992 & 0.7220 & 0.5711 & 0.3135 \\
\hline & $n$ & 24 & 19 & 19 & 19 & 19 & 19 & 19 & 19 & 19 & 19 & 19 \\
\hline \multirow[t]{3}{*}{$A \beta 1-42$} & r & $0.426^{*}$ & 0.145 & 0.085 & 0.176 & 0.057 & 0.079 & 0.371 & 0.290 & 0.103 & 0.048 & 0.432 \\
\hline & $p$ & 0.0379 & 0.5530 & 0.7298 & 0.4706 & 0.8159 & 0.7493 & 0.1175 & 0.2285 & 0.6739 & 0.8441 & 0.0651 \\
\hline & $n$ & 24 & 19 & 19 & 19 & 19 & 19 & 19 & 19 & 19 & 19 & 19 \\
\hline \multirow[t]{3}{*}{ Total tau } & $r$ & 0.053 & 0.088 & -0.227 & 0.111 & 0.268 & $0.461^{*}$ & 0.302 & -0.030 & 0.288 & 0.116 & $0.547^{*}$ \\
\hline & $p$ & 0.8056 & 0.7199 & 0.3502 & 0.6514 & 0.2671 & 0.0469 & 0.2094 & 0.9016 & 0.2314 & 0.6365 & 0.0155 \\
\hline & $n$ & 24 & 19 & 19 & 19 & 19 & 19 & 19 & 19 & 19 & 19 & 19 \\
\hline \multirow[t]{3}{*}{ P-tau181p } & $r$ & -0.292 & 0.051 & -0.234 & -0.287 & -0.065 & 0.112 & -0.054 & -0.294 & -0.327 & -0.403 & 0.280 \\
\hline & $p$ & 0.1877 & 0.8459 & 0.3660 & 0.2635 & 0.8047 & 0.6678 & 0.8365 & 0.2516 & 0.2005 & 0.1085 & 0.2759 \\
\hline & $n$ & 22 & 17 & 17 & 17 & 17 & 17 & 17 & 17 & 17 & 17 & 17 \\
\hline
\end{tabular}

\footnotetext{
*: $p<0.05,{ }^{* *}: p<0.01$
}

Abbreviations: Total aS, Total a-synuclein; O-aS, Oligomeric a-synuclein; P-tau181p, tau phosphorylated at threonine 181; MoCA, the Montreal Cognitive Assessment; COGNISTAT, the Neurobehavioral Cognitive Status Examination 
Table 3 Spearman correlation coefficients among CSF protein levels

\begin{tabular}{lllllll}
\hline & & Total aS & O-aS & A $\beta 1-42$ & Total tau & P-tau181p \\
\hline Total aS & $r$ & 1.000 & & & & \\
& $p$ & - & & & & \\
& $\mathrm{n}$ & 27 & & & & \\
O-aS & $r$ & 0.074 & 1.000 & & & \\
& $p$ & 0.7142 & - & & & \\
& $\mathrm{n}$ & 27 & 27 & & & \\
Aß1-42 & $r$ & $0.613^{* * *}$ & 0.375 & 1.000 & & \\
& $p$ & 0.0007 & 0.0536 & - & & \\
& $\mathrm{n}$ & 27 & 27 & 27 & & \\
Total tau & $r$ & $0.839^{* * *}$ & -0.108 & 0.365 & 1.000 & \\
& $p$ & 0.0000 & 0.5916 & 0.0609 & - & 25 \\
& $\mathrm{n}$ & 27 & 27 & 27 & 27 & \\
P-tau181p & $r$ & $0.614^{* *}$ & -0.022 & 0.138 & $0.665^{* * *}$ & 1.000 \\
& $p$ & 0.0011 & 0.9170 & 0.5110 & 0.0003 & - \\
& $\mathrm{n}$ & 25 & 25 & 25 & 25 & 25 \\
\hline
\end{tabular}

${ }^{* *}: p<0.01, * * *: p<0.001$

Abbreviations: Total aS, Total a-synuclein; O-aS, Oligomeric a-synuclein;

P-tau181p, tau phosphorylated at threonine 181

COGNISTAT subscores for language-naming and judgment (both $p<0.05$ ); and P-tau181p was negatively correlated with UPDRS scores for part III, rigidity, and bradykinesia (all $p<0.05$ ).

Spearman correlation coefficients among CSF protein levels are shown in Table 3. CSF levels of total $\alpha$ S were positively correlated with those of $\mathrm{A} \beta 1-42 \quad(p<0.001$, Fig. 2a), total tau $(p<0.001$, Fig. $2 \mathrm{~b})$, and P-tau181p $(p<0.01$, Fig. 2c). CSF levels of $\mathrm{O}-\alpha \mathrm{S}$ showed no correlation with those of any other proteins.

\section{Discussion}

The results of this study showed that CSF levels of total $\alpha S$ are negatively correlated with UPDRS part III and bradykinesia scores, which indicates that these motor functions worsen as the CSF level of total $\alpha$ S decreases. This result agrees with those from the Parkinson's Progression Marker's Initiative (PPMI) study, which showed that the CSF $\alpha \mathrm{S}$ level is negatively correlated with MDSUPDRS part III (motor score) and the Hoehn and Yahr scale in drug-naive PD patients [23]. Therefore, total $\alpha S$ in CSF decreases with progression of PD, which may be due to aggregation and intracellular accumulation of $\alpha S$ $[4,5,24]$. In the present study, the CSF level of total $\alpha S$ showed a positive correlation with the COGNISTAT subtest of judgment, which suggests worsening judgment as the CSF total $\alpha S$ level decreases. This subtest requires patients to explain how to overcome a presented abnormal and critical situation; that is, it evaluates frontal/ executive function. Our results are consistent with
Table 4 Patient background

\begin{tabular}{|c|c|c|}
\hline Male: Female & $14: 13$ & \\
\hline Age (years) & $72.3 \pm 9.2$ & (range 47-84) \\
\hline Education (years) & $12.2 \pm 3.2$ & (range 3-16) \\
\hline \multirow{7}{*}{$\begin{array}{l}\text { Duration from symptom } \\
\text { onset (years) }\end{array}$} & $1.3 \pm 1.2$ & \\
\hline & $(<1$ year & 7 persons) \\
\hline & $(\geq 1,<2$ years & 12 persons) \\
\hline & $(\geq 2,<3$ years & 4 persons) \\
\hline & $(\geq 3,<4$ years & 3 persons) \\
\hline & $(\geq 4,<5$ years & 0 person) \\
\hline & $(\geq 5,<6$ years & 1 person) \\
\hline \multicolumn{3}{|l|}{ Clinical assessment scores } \\
\hline \multicolumn{3}{|l|}{ UPDRS } \\
\hline Part III (motor score) & $16.7 \pm 8.2$ & (range 5-31) \\
\hline Tremor & $2.6 \pm 2.6$ & (range 0-10) \\
\hline Rigidity & $3.0 \pm 2.3$ & (range 0-10) \\
\hline Bradykinesia & $6.4 \pm 4.4$ & (range 0-16) \\
\hline Gait & $2.5 \pm 2.0$ & (range $0-7$ ) \\
\hline Postural instability & $2.4 \pm 1.9$ & (range 0-6) \\
\hline MoCA & $21.7 \pm 5.5$ & (range 9-28) \\
\hline \multicolumn{3}{|l|}{ COGNISTAT } \\
\hline Orientation & $8.9 \pm 1.3$ & (range 6-10) \\
\hline Attention & $6.3 \pm 3.8$ & (range 1-10) \\
\hline $\begin{array}{l}\text { Language- } \\
\text { comprehension }\end{array}$ & $8.7 \pm 2.9$ & (range 1-10) \\
\hline Language-repetition & $8.6 \pm 2.3$ & (range 4-11) \\
\hline Language-naming & $9.0 \pm 1.6$ & (range 5-10) \\
\hline Construction & $7.5 \pm 1.8$ & (range 4-11) \\
\hline Memory & $7.5 \pm 1.7$ & (range 5-10) \\
\hline Calculation & $8.6 \pm 2.5$ & (range 2-10) \\
\hline Similarity & $9.1 \pm 1.2$ & (range 6-11) \\
\hline Judgement & $9.8 \pm 1.3$ & (range $7-12$ ) \\
\hline \multicolumn{3}{|l|}{ CSF protein levels } \\
\hline Total as (pg/ml) & $1517.3 \pm 654.3$ & (range 573-3387) \\
\hline O-aS (RLU/s) & $107,019.5 \pm 20,203.1$ & (range $74,867-161,685$ ) \\
\hline $\mathrm{A} \beta 1-42(\mathrm{pg} / \mathrm{ml})$ & $427.1 \pm 159.7$ & (range 206.4-724.5) \\
\hline Total tau (pg/ml) & $38.4 \pm 21.2$ & (range 11.2-93.9) \\
\hline P-tau181p (pg/ml) & $15.3 \pm 6.1$ & (range 5.8-29.9) \\
\hline
\end{tabular}

Scores are shown as Mean \pm Standard Deviation. Abbreviations: UPDRS, Unified Parkinson's Disease Rating Scale; MoCA, the Montreal Cognitive Assessment; COGNISTAT, the Neurobehavioral Cognitive Status Examination; Total aS, Total a-synuclein; O-aS, Oligomeric a-synuclein; P-Tau181p, tau phosphorylated at threonine 181

those in Skogseth et al., in which it was also found that a lower CSF $\alpha$ S level was associated with reduced performance on executive function [25].

Although $\mathrm{O}-\alpha \mathrm{S}$ is toxic and mediates neural damage [1-3], no clinical symptom correlated with the CSF level 
(a) UPDRS

(part III)

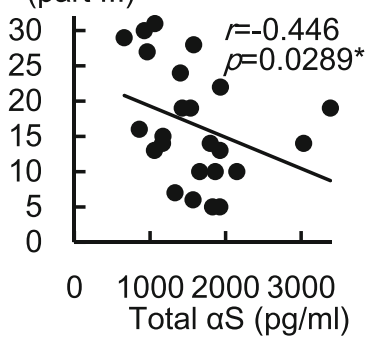

(b) UPDRS

(bradykinesia)

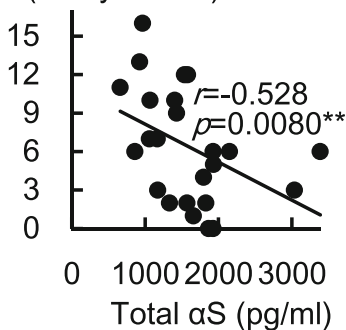

(c) COGNISTAT

(judgement)

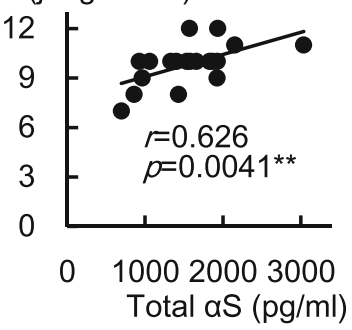

*: $p<0.05,{ }^{* *}: p<0.01$

Fig. 1 Distribution of CSF levels of total a-synuclein and clinical assessment scores. The graphs show CSF levels of total aS with a UPDRS part III scores, b UPDRS subscores for bradykinesia, and c COGNISTAT judgement scores. Abbreviations: Total aS, Total a-synuclein; UPDRS, Unified Parkinson's Disease Rating Scale; COGNISTAT, Neurobehavioral Cognitive Status Examination

of $\mathrm{O}-\alpha \mathrm{S}$ in this study. In most studies of CSF O- $\alpha \mathrm{S}$, the level has been shown to be higher in PD patients than in normal controls [4-6]. Our results suggest that CSF levels of $\mathrm{O}-\alpha \mathrm{S}$ do not necessarily correlate with clinical symptoms or the extent of neuronal damage in a cross-sectional study. There may be a time lag between dynamics of CSF levels of $\mathrm{O}-\alpha \mathrm{S}$ and changes in clinical symptoms. On the other hand, $\mathrm{O}-\alpha \mathrm{S}$ accumulates in the brain, and therefore, intracellular $\mathrm{O}-\alpha \mathrm{S}$ may affect clinical symptoms in $\mathrm{PD}$ patients and may be related to motor and cognitive functions. However, the intraneuronal level of $\mathrm{O}-\alpha \mathrm{S}$ cannot be measured in a clinical setting.

The CSF levels of total tau and P-tau181p as well as total $\alpha \mathrm{S}$ were negatively correlated with bradykinesia scores. Bradykinesia is the earliest and most fundamental motor symptom in PD [11]. These correlations show that as the disease progresses, CSF levels of total tau, Ptau181p and total $\alpha \mathrm{S}$ concurrently decrease. Similar associations of CSF total tau and $\alpha \mathrm{S}$ with motor severity in de novo PD patients were found in the PPMI study [23]. In our study, CSF levels of total tau and P-tau181p also showed strong positive correlations with that of total $\alpha \mathrm{S}$.
Waxman et al. showed that $\alpha \mathrm{S}$ can induce aggregation of tau, and that phosphorylation of these aggregates then progresses in vivo [26]. Guo et al. showed similar results for $\alpha \mathrm{S}$ cross-seeding tau aggregation in vivo [27]. Ishizawa et al. found tau- and phosphorylated tau-positive Lewy bodies in immunostaining of postmortem brain in Lewy body disease patients [28]. These findings suggest that tau and phosphorylated tau both aggregate with $\alpha S$, which explains the correlation of their decreased CSF levels. Correlations of CSF levels of both total tau and P-tau181p with total $\alpha \mathrm{S}$ were stronger than those with bradykinesia. This suggests that the interaction between these proteins is primary, and that bradykinesia then emerges. In $\mathrm{AD}$, the CSF level of tau is increased, which may be due to releases of tau protein from damaged neurons into the CSF [7]. Although PD and AD are both neurodegenerative disease, the dynamics of tau may differ in the two diseases.

In the present study, the CSF level of $A \beta 1-42$, an $\mathrm{AD}$ biomarker, was positively correlated with MoCA score, which suggests that cognitive function deteriorates as the CSF A $1-42$ level decreases. In $\mathrm{AD}$, a decrease in CSF $A \beta 1-42$ is thought to be due to its aggregation in
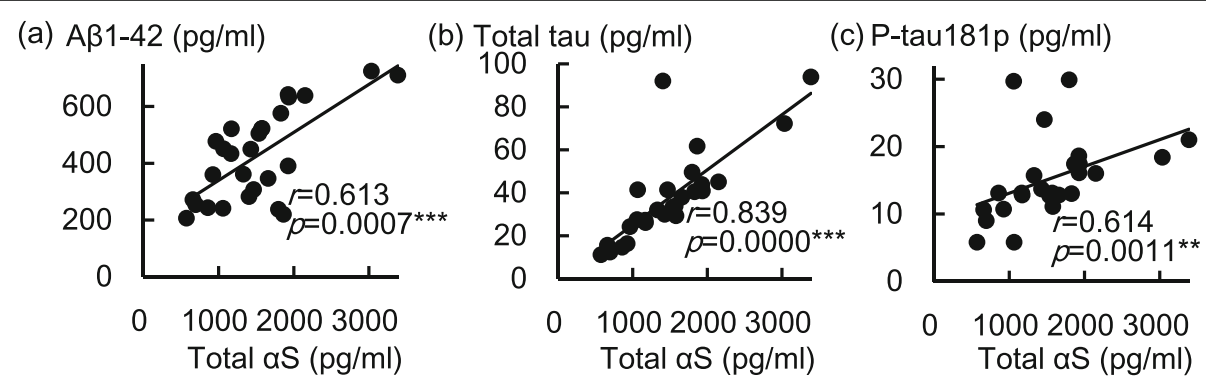

${ }^{* *}: p<0.01,{ }^{* * *}: p<0.001$

Fig. 2 Distribution of CSF levels of total a-synuclein and CSF protein levels. The graphs show CSF levels of total aS with CSF levels of a A $1-42$, b total tau, and c P-tau181p. Abbreviations: Total aS, Total a-synuclein; A 1-42, amyloid $\beta$ (A $\beta$ )1-42; P-tau181p, tau phosphorylated at threonine 181; O-aS, oligomeric a-synuclein 
the brain [29]. Therefore, our results suggest that cognitive function deteriorates as aggregation of $A \beta 1-42$ progresses. However, the CSF level of A $\beta 1-42$ showed a stronger positive correlation with that of total $\alpha S$ in the present study. This suggests that $\alpha S$ and $A \beta 1-42$ interact. It was previously shown that $A \beta$ enhances $\alpha \mathrm{S}$ accumulation and neuronal deficits in vivo [30], and an in vitro study indicated that $\mathrm{A} \beta$ and $\alpha \mathrm{S}$ might interact directly to form pore-like oligomers that contribute to neurodegeneration [31]. We previously showed that $\alpha \mathrm{S}$ and A $\beta 1-42$ act as seeds and affect each other's aggregation pathways in vivo, suggesting a molecular interaction between AD and PD [32]. Co-existence of $\alpha \mathrm{S}$ and $\mathrm{A} \beta 1-42$ deposits in human brain is found in pathological studies, and PD patients present with an AD pathology of amyloid deposition, such as senile plaque [8]. Lewy bodies are found in $56.8 \%$ of $\mathrm{AD}$ cases [33], $\mathrm{A} \beta$ deposits are distributed throughout the medial temporal lobe in DLB patients [34], and $A \beta$ deposition is associated with enhanced cortical $\alpha S$ lesions in postmortem brain of PD patients [35]. Therefore, $\alpha \mathrm{S}$ and A $\beta 1-42$ co-aggregate and their CSF levels concurrently decrease. The stronger correlation of the CSF level of A $\beta 1-42$ with the CSF level of total $\alpha \mathrm{S}$ compared to that with the MoCA total score suggests that the interaction between these proteins is the primary event, with subsequent emergence of cognitive deterioration.

In the PPMI study, a correlation between CSF levels of $\alpha \mathrm{S}$ and A $\beta 1-42$ was not observed [23]. The PPMI study included earlier drug-naïve PD patients diagnosed within no more than 2.6 years (median 0.4 years) from onset. In contrast, the present study included many PD patients with a longer duration from onset. Therefore, we calculated the correlation coefficients in patients with a shorter disease duration. The significant correlation between total $\alpha \mathrm{S}$ and $\mathrm{A} \beta 1-42$ was preserved in patients with a disease durations of $<1$ year $(n=7, r=0.929, p<0.01)$, but not in patients with a disease durations of $\geq 1$ year $(n=20, \mathrm{r}=$ $0.284, p=0.225$ ). On the other hand, CSF level of total $\alpha S$ correlated with total tau $(\mathrm{n}=20, \mathrm{r}=0.767, p=0.000)$ and P-tau181p $(n=18, \mathrm{r}=0.564, p=0.015)$ in patients with a disease durations of $\geq 1$ year and these results agree the PPMI study [23]. Difference in correlation of CSF level of total $\alpha \mathrm{S}$ between $\mathrm{A} \beta 1-42$ and total and phosphorylated tau proteins in patients with a disease duration of $\geq 1$ year suggests dynamics of these proteins differ. A possible hypothesis to explain this difference is as follows. In earlier phase which was shown to be a disease duration of $<1$ year in our study, these intracellular proteins aggregate as mentioned above. In later phase, neurocytotoxic change progress to promote the aggregation of extracellular $A \beta 1-$ 42 , and the aggregates of $A \beta 1-42$ pull out $\alpha \mathrm{S}$ from neurons. Consequently, correlation of CSF levels of $\alpha S$ and A $\beta 1-42$ becomes unclear. However the turning point of the earlier to later phase may differ in each patients and/ or cohorts due to unknown factors. Majority of participants in the PPMI study may have the pathophysiology of the later phase as hypothesized above. The reasons for the difference in correlations between our study and the PPMI study are uncertain. Future studies in other cohorts are required to investigate this correlation and elucidate the pathology of PD.

This study includes only drug-naïve PD patients and the effect of medication is eliminated. Our results support a central role for interaction and aggregation of $\alpha \mathrm{S}$ with A $\beta 1-42$, tau, and phosphorylated tau in the pathogenesis of PD. However, the study has limitations. The number of patients is relatively small and we did not include a normal control group. A larger number of participants and control group would have made our conclusions more comprehensive and meaningful. However, recruitment of patients who agree to lumbar puncture is difficult, since most patients with parkinsonism want to be examined without lumbar puncture, and we could not recruit healthy volunteers who agreed to undergo lumbar puncture. Consequently, only 27 patients agreed to participate in the study. However, therapies targeting pathogenic proteins are under development, and knowledge of the relationship between pathogenic proteins and clinical symptoms is important. Therefore, we believe our report is significant and contributes to understanding of the pathophysiology of PD.

\section{Conclusions}

CSF levels of $\alpha \mathrm{S}$ correlate with some clinical symptoms and with CSF levels of A $\beta 1-42$, total tau and P-tau181p in drug-naïve PD patients. These correlations suggest a central role for interaction and aggregation of $\alpha \mathrm{S}$ with A $\beta 1-42$, tau, and phosphorylated tau in the pathogenesis of PD. Although O- $\alpha \mathrm{S}$ has been shown to have neurotoxic effects, CSF levels do not reflect clinical symptoms or levels of other proteins in cross-sectional assessment.

\section{Additional file}

Additional file 1: All data used during this study. (XLSX 13 kb)

\section{Abbreviations}

AD: Alzheimer's Disease; A $\beta$ : amyloid Amyloid $\beta$; COGNISTAT: the The Neurobehavioral Cognitive Status Examination; CSF: Cerebrospinal Fluid; DLB: Dementia with Lewy Bodies; ELISA: Enzyme-Linked Immunosorbent Assay; MCl: Mild Cognitive Impairment; MoCA: Montreal Cognitive Assessment; O-aS: Oligomeric a-synuclein; PD: Parkinson's Disease; PDD: Parkinson's Disease with Dementia; PD-MCl: Parkinson's Disease with Mild Cognitive Impairment; PPMI: Parkinson's Progression Marker's Initiative; P-tau181p: tau Tau phosphorylated at threonine 181; SD: Standard Deviation: UPDRS: the The Unified Parkinson's Disease Rating Scale; aS: a-synuclein

\section{Acknowledgements}

We thank C.P. M. Miyanohara for performing the neuropsychological examination. 


\section{Author's contributions}

Study design and concept: HM, KO. Acquisition of clinical data: HM, AM, HO, YO, YS, SY. Analyses of CSF: TTokuda, TO, OE, TTsukie, TI. Statistical analysis and interpretation of data: $\mathrm{HM}, \mathrm{YO}, \mathrm{KO}$. Drafting of the manuscript: $\mathrm{HM}$, TTokuda, TO, TTsukie, TI. All authors read and approved the final version of the manuscript.

\section{Funding}

Assessments of CSF concentration of a-Synuclein and its oligomer by TTokuda were supported by Japan Agency for Medical Research and Development (AMED: grant number: 18dk0207030h0003). Assessments of CSF concentration of A $\beta 1-42$, total tau and P-tau181p by TI were supported by AMED (grant number:18 dm0107143). OE lab is supported by startup funding from QBRI (grant number:VR98).

\section{Availability of data and materials}

All data used during this study are included in the Additional file 1.

\section{Ethics approval and consent to participate}

The Ethics Committee of Showa University School of Medicine approved this study, and it was performed according to the Declaration of Helsinki. Written informed consent was obtained from all participants prior to enrolment.

\section{Consent for publication}

Not applicable.

\section{Competing interests}

The authors declare that they have no competing interests.

\section{Author details}

'Department of Neurology, School of Medicine, Showa University, 1-5-8 Hatanodai, Shinagawa-ku, Tokyo 142-8666, Japan. ${ }^{2}$ Department of Molecular Pathobiology of Brain Diseases, Kyoto Prefectural University of Medicine, 465 Kajii-cho, Kawaramachi-Hirokoji, Kamikyo-ku, Kyoto 602-8566, Japan. ${ }^{3}$ Neurological Disorders Research Center, Qatar Biomedical Research Institute (QBRI), Hamad Bin Khalifa University (HBKU), Education City, Qatar Foundation, P.O. Box 5825, Doha, Qatar. ${ }^{4}$ Department of Neurology, Kyoto Prefectural University of Medicine, 465 Kajii-cho, Kawaramachi-Hirokoji, Kamikyo-ku, Kyoto 602-8566, Japan. ${ }^{5}$ Department of Molecular Genetics, Brain Research Institute, Niigata University, 1-757 Asahimachi, Chuo-ku, Niigata 951-8585, Japan.

\section{Received: 4 January 2019 Accepted: 29 May 2019}

\section{Published online: 04 June 2019}

\section{References}

1. Ono K. The oligomer hypothesis in a-Synucleinopathy. Neurochem Res. 2017:42(12):3362-71

2. Forloni G, Artuso V, La Vitola P, Balducci C. Oligomeropathies and pathogenesis of Alzheimer and Parkinson's diseases. Mov Disord. 2016;31(6): 771-81.

3. Lashuel HA, Overk CR, Oueslati A, Masliah E. The many faces of a-synuclein: from structure and toxicity to therapeutic target. Nat Rev Neurosci. 2013; 14(1):38-48

4. Parnetti L, Cicognola C, Eusebi P, Chiasserini D. Value of cerebrospinal fluid a-synuclein species as biomarker in Parkinson's diagnosis and prognosis. Biomark Med. 2016:10(1):35-49.

5. Majbour NK, Vaikath NN, van Dijk KD, Ardah MT, Varghese S, Vesterager LB, Montezinho LP, Poole S, Safieh-Garabedian B, Tokuda T, Teunissen CE, Berendse HW, van de Berg WD, El-Agnaf OM. Oligomeric and phosphorylated a-synuclein as potential CSF biomarkers for Parkinson's disease. Mol Neurodegener. 2016;11:7.

6. Tokuda T, Qureshi MM, Ardah MT, Varghese S, Shehab SA, Kasai T, Ishigami N, Tamaoka A, Nakagawa M, El-Agnaf OM. Detection of elevated levels of asynuclein oligomers in CSF from patients with Parkinson disease. Neurology. 2010;75(20):1766-72.

7. Agarwal R, Tripathi CB. Diagnostic utility of CSF tau and $A \beta(42)$ in dementia: a meta-analysis. Int J Alzheimers Dis. 2011:2011:503293. https://doi.org/10.4061/2011/503293.
8. Apaydin H, Ahlskog JE, Parisi JE, Boeve BF, Dickson DW. Parkinson disease neuropathology: later-developing dementia and loss of the levodopa response. Arch Neurol. 2002;59(1):102-12.

9. Stav AL, Aarsland D, Johansen KK, Hessen E, Auning E, Fladby T. Amyloid- $\beta$ and a-synuclein cerebrospinal fluid biomarkers and cognition in early Parkinson's disease. Parkinsonism Relat Disord. 2015;21(7):758-64.

10. Kouri N, Whitwell JL, Josephs KA, Rademakers R, Dickson DW. Corticobasal degeneration: a pathologically distinct $4 R$ tauopathy. Nat Rev Neurol. 2011; 7(5):263-72.

11. Postuma RB, Berg D, Stern M, Poewe W, Olanow CW, Oertel W, Obeso J, Marek K, Litvan I, Lang AE, Halliday G, Goetz CG, Gasser T, Dubois B, Chan P, Bloem BR, Adler CH, Deuschl G. MDS clinical diagnostic criteria for Parkinson's disease. Mov Disord. 2015;30(12):1591-601.

12. McKeith IG, Boeve BF, Dickson DW, Halliday G, Taylor JP, Weintraub D, Aarsland D, Galvin J, Attems J, Ballard CG, Bayston A, Beach TG, Blanc F, Bohnen N, Bonanni L, Bras J, Brundin P, Burn D, Chen-Plotkin A, Duda JE, ElAgnaf O, Feldman H, Ferman TJ, Ffytche D, Fujishiro H, Galasko D, Goldman JG, Gomperts SN, Graff-Radford NR, Honig LS, Iranzo A, Kantarci K, Kaufer D, Kukull W, Lee VMY, Leverenz JB, Lewis S, Lippa C, Lunde A, Masellis M, Masliah E, McLean P, Mollenhauer B, Montine TJ, Moreno E, Mori E, Murray M, O'Brien JT, Orimo S, Postuma RB, Ramaswamy S, Ross OA, Salmon DP, Singleton A, Taylor A, Thomas A, Tiraboschi P, Toledo JB, Trojanowski JQ, Tsuang D, Walker Z, Yamada M, Kosaka K. Diagnosis and management of dementia with Lewy bodies: fourth consensus report of the DLB consortium. Neurology. 2017;89(1):88-100.

13. Mollenhauer B, Locascio JJ, Schulz-Schaeffer W, Sixel-Döring F, Trenkwalder C, Schlossmacher MG. a-Synuclein and tau concentrations in cerebrospinal fluid of patients presenting with parkinsonism: a cohort study. Lancet Neurol. 2011;10(3):230-40.

14. Mollenhauer B, Trautmann E, Taylor P, Manninger P, Sixel-Döring F, Ebentheuer J, Trenkwalder C, Schlossmacher MG. Total CSF a-synuclein is lower in de novo Parkinson patients than in healthy subjects. Neurosci Lett. 2013;532:44-8

15. El-Agnaf OM, Salem SA, Paleologou KE, Curran MD, Gibson MJ, Court JA, Schlossmacher MG, Allsop D. Detection of oligomeric forms of a-synuclein protein in human plasma as a potential biomarker for Parkinson's disease. FASEB J. 2006;20(3):419-25.

16. Shaw LM, Vanderstichele $H$, Knapik-Czajka M, Figurski M, Coart E, Blennow K Soares H, Simon AJ, Lewczuk P, Dean RA, Siemers E, Potter W, Lee VM, Alzheimer's Disease Neuroimaging Initiative TJQ. Qualification of the analytical and clinical performance of CSF biomarker analyses in ADNI. Acta Neuropathol. 2011;121(5):597-609.

17. Olsson A, Vanderstichele $H$, Andreasen N, De Meyer G, Wallin A, Holmberg $B$, Rosengren L, Vanmechelen E, Blennow K. Simultaneous measurement of $\beta$-amyloid(1-42), total tau, and phosphorylated tau (Thr181) in cerebrospinal fluid by the XMAP technology. Clin Chem. 2005;51(2):336-45.

18. Iwatsubo T, Iwata A, Suzuki K, Ihara R, Arai H, Ishii K, Senda M, Ito K, Ikeuchi T, Kuwano R, Matsuda H, Alzheimer's Disease Neuroimaging Initiative J, Sun CK, Beckett LA, Petersen RC, Weiner MW, Aisen PS, Donohue MC, Alzheimer's Disease Neuroimaging I. Japanese and north American Alzheimer's Disease Neuroimaging Initiative studies: harmonization for international trials. Alzheimers Dement. 2018;14(8):1077-87.

19. Movement Disorder Society Task Force on Rating Scales for Parkinson's Disease. The unified Parkinson's Disease rating scale (UPDRS): status and recommendations. Mov Disord. 2003;18(7):738-50.

20. Kiernan RJ, Mueller J, Langston JW, Van Dyke C. The neurobehavioral cognitive status examination: a brief but quantitative approach to cognitive assessment. Ann Intern Med. 1987;107(4):481-5.

21. Matsuda O, Kumazawa Y, Sakuraba Y, Matsuda H, Nakatani M, Saito M. The development of the Japanese version of the neurobehavioral cognitive status examination (NCSE), second report. Jpn J Geriatr psychiatry. 2003; 14(4):475-83 Article in Japanese

22. Murakami H, Fujita K, Futamura A, Sugimoto A, Kobayakawa M, Kezuka M, Midorikawa A, Kawamura M. The Montreal cognitive assessment and neurobehavioral cognitive status examination are useful for screening mild cognitive impairment in Japanese patients with Parkinson's disease. Neurol Clin Neurosci. 2013;1(3):103-8.

23. Kang $J H$, Irwin DJ, Chen-Plotkin AS, Siderowf A, Caspell C, Coffey CS, Waligórska T, Taylor P, Pan S, Frasier M, Marek K, Kieburtz K, Jennings D, Simuni T, Tanner CM, Singleton A, Toga AW, Chowdhury S, Mollenhauer B, Trojanowski JQ, Shaw LM. Parkinson's progression markers Initiative. 
Association of cerebrospinal fluid $\beta$-amyloid 1-42, T-tau, P-tau181, and asynuclein levels with clinical features of drug-naive patients with early Parkinson disease. JAMA Neurol. 2013;70(10):1277-87.

24. Tokuda T, Salem SA, Allsop D, Mizuno T, Nakagawa M, Qureshi MM, Locascio JJ, Schlossmacher MG, El-Agnaf OM. Decreased a-synuclein in cerebrospinal fluid of aged individuals and subjects with Parkinson's disease. Biochem Biophys Res Commun. 2006;349(1):162-6.

25. Skogseth RE, Bronnick K, Pereira JB, Mollenhauer B, Weintraub D, Fladby T, Aarsland D. Associations between cerebrospinal fluid biomarkers and cognition in early untreated Parkinson's Disease. J Park Dis. 2015;5(4):783-92.

26. Waxman EA, Giasson BI. Induction of intracellular tau aggregation is promoted by a-synuclein seeds and provides novel insights into the hyperphosphorylation of tau. J Neurosci. 2011;31(21):7604-18.

27. Guo JL, Covell DJ, Daniels JP, Iba M, Stieber A, Zhang B, Riddle DM, Kwong LK, Xu Y, Trojanowski JQ, Lee VM. Distinct a-synuclein strains differentially promote tau inclusions in neurons. Cell. 2013;154(1):103-17.

28. Ishizawa T, Mattila P, Davies P, Wang D, Dickson DW. Colocalization of tau and a-synuclein epitopes in Lewy bodies. J Neuropathol Exp Neurol. 2003; 62(4):389-97.

29. Strozyk D, Blennow K, White LR, Launer LJ. CSF A 42 levels correlate with amyloid-neuropathology in a population-based autopsy study. Neurology. 2003:60(4):652-6.

30. Masliah E, Rockenstein E, Veinbergs I, Sagara Y, Mallory M, Hashimoto M. Mucke L. beta-amyloid peptides enhance alpha-synuclein accumulation and neuronal deficits in a transgenic mouse model linking Alzheimer's disease and Parkinson's disease. Proc Natl Acad Sci U S A. 2001;98(21):12245-50.

31. Tsigelny IF, Sharikov Y, Miller MA, Masliah E. Mechanism of alpha-synuclein oligomerization and membrane interaction: theoretical approach to unstructured proteins studies. Nanomedicine. 2008;4(4):350-7.

32. Ono K, Takahashi R, lkeda T, Yamada M. Cross-seeding effects of amyloid $\beta$ protein and a-synuclein. J Neurochem. 2012;122(5):883-90.

33. Hamilton RL. Lewy bodies in Alzheimer's disease: a neuropathological review of 145 cases using alpha-synuclein immunohistochemistry. Brain Pathol. 2000;10(3):378-84

34. Armstrong RA, Cairns NJ, Lantos PL. Beta-amyloid (a beta) deposition in the medial temporal lobe of patients with dementia with Lewy bodies. Neurosci Lett. 1997:227(3):193-6.

35. Pletnikova O, West N, Lee MK, Rudow GL, Skolasky RL, Dawson TM, Marsh L, Troncoso JC. Abeta deposition is associated with enhanced cortical alphasynuclein lesions in Lewy body diseases. Neurobiol Aging. 2005;26(8):1183-92.

\section{Publisher's Note}

Springer Nature remains neutral with regard to jurisdictional claims in published maps and institutional affiliations.

Ready to submit your research? Choose BMC and benefit from:

- fast, convenient online submission

- thorough peer review by experienced researchers in your field

- rapid publication on acceptance

- support for research data, including large and complex data types

- gold Open Access which fosters wider collaboration and increased citations

- maximum visibility for your research: over $100 \mathrm{M}$ website views per year

At $\mathrm{BMC}$, research is always in progress.

Learn more biomedcentral.com/submissions 